International Journal of English Literature and Social Sciences
Vol-6, Issue-2; Mar-Apr, 2021
Journal Home Page Available: https://ijels.com/
Journal DOI: $\underline{10.22161 / \text { ijels }}$

\title{
The Art of Government: Approaches to the Notion of Legitimacy in Inca Society
}

\author{
Rafael Vila
}

Faculty of Social Sciences, University of Huamanga, Perú

Received: 11 Dec 2020; Received in revised form: 11 Feb 2021; Accepted: 05 Mar 2021; Available online: 28 Mar 2021

(C2021 The Author(s). Published by Infogain Publication. This is an open access article under the CC BY license

(https://creativecommons.org/licenses/by/4.0/).

\begin{abstract}
Inca society is one of the most important links in the development of Andean societies; therefore, it constitutes a key piece to understand part of the social problems that the mentioned region is going through in the XXI century. Of the wide spectrum of problems that can be located, the idea of a system that does not feel legitimate by society is of particular interest. In this paper, we study the way in which the Inca power structure was configured and the repercussion that this configuration could have on the perception of the dominated class towards the ruling class, and use this perception in turn to arrive at an approximate idea on how valid those who lived under its yoke could come to consider this system of domination. This task also seeks to clarify the experiences of legitimacy of a past society to help understand the same issue in the Latin American society of the XXI century.
\end{abstract}

Keywords - Legitimacy, Inca, domination, Latin American.

\section{INTRODUCTION}

The strong processes of social upheaval that the Andean societies of the XXI century are going through give evidence of the existence of a serious problem of legitimation of contemporary democratic systems. The explanation of this phenomenon constitutes a global task, where modern political science, in support of other sciences that study human behavior, faces the enormous challenge of finding a consensus that allows to legitimize the democracy of different countries in the societies in which they unwrap. In the Latin American region, this issue becomes particularly complex, insofar as the spectrum of corruption is practically rooted in the collective social memory as one of the main problems of legitimizing the system. It is perhaps at this point, in the face of the accelerated advance of modern society, that we should stop focusing solely on the problems of the present and return to reflect on the most primitive conceptions of the question addressed. We should perhaps ask ourselves more basic questions such as: What is it that makes a system really legitimate? Or in any case, what is it that complicates its legitimation so much? These are questions that seem exclusive to political science, but historical sciences can contribute important aspects to take into account, insofar as they reveal the roots and evolution of a society, and it is from these contributions that we can learn from the mistakes made, or enrich ourselves by the successes of past societies. Latin America has its own vast past configured where obviously we can find much of what helps us understand current Latin American society. In this line of thought, the Inca society was one of the greatest empires in the world, surprising many researchers how particular its institutions and the functioning of its society; Therefore, the study of this civilization gives rise to valuable contributions on the understanding of the evolution of current societies in much of Latin America, this empire having encompassed several current countries of the aforementioned region. But it is also necessary to understand that the power structure is not isolated in a specific and closed institution; since, as it will be seen later, the interrelation of the foci of the Inca society is what ends up configuring its moral values and subsequent pragmatic capitalization in a broad framework of social and economic relations. This understanding helps greatly and is necessary to be able to speak of a "legitimate or illegitimate system". 


\section{APPROACHES TO THE NOTION OF LEGITIMACY}

Before starting any discussion, it is necessary to define some key concepts to avoid confusion or any misrepresentation of ideas. The term "legitimacy" in reality is quite controversial, but even among the different perspectives that will be addressed, some general characteristics emerge. For the purposes of this paper, special emphasis will be placed on the notions of legitimacy developed by Max Weber. It is borne in mind that the ideas of this important German sociologist were fundamentally oriented to understanding and explaining the state in modern societies, so the task of semantic contextualization will be used with special care insofar as it is kept in mind that European ideas are applied to PreColumbian society must be an extremely careful task.

In an analysis of Weber, Francisco Beltrán (2000) goes so far as to argue that "legitimacy is, then, a probability that the dominators justify the validity of their dominance, in such a way that it can be 'represented' in the dominated, not simply as an awareness that the existing order is 'good' or 'fair', but rather that it is strong enough to impose itself on it." The idea that legitimacy can be understood as the way in which, in a context in which a person or social group has dominion over another, is highlighted, how this other feels this dominance valid. The reason why this being dominated does not find reasons to feel that he is being belittled, but rather that he even feels satisfied for being under that domination. The opposite can also be deduced, a system can become illegitimate if the dominated caste does not consider valid the causes by which another exercises power over them. "By legitimate order we understand a valid order ... [however] the " validity' that Weber points out does not have to do with logical or moral validity, it is about the sociological validity that consists in that an order has empirical efficacy, it is that is to say, that it be obeyed in practice" (Martínez-Ferro, 2010). That is, legitimacy would not be specifically on the perception that people have about the effectiveness of their rulers or ruling class, but on a relationship that is forged in people's own values and conception of the world, and that they must find a relationship with the system under which they exercise their domination.

Later on, it will be seen that efficiency, for example, in the redistribution of resources in relation to people's quality of life, does influence the legitimation of the system, but in no way constitutes its final catalyst. That is why Luis Oro (2002), studying Weber's ideas, goes so far as to affirm that "a legitimate order beyond a rational pact made based on reciprocal convenience ... does not constitute a mere utilitarian agreement between interested parties".

This is why the idea of legitimacy should be discarded from now on as a commercial agreement that hopes to see which party benefits the most. Thus, it is quite evident that the relationship between the permanence or temporary permanence of a system is in a directly proportional relationship with its level of legitimacy.

In political science notions very similar to those that can be obtained by interpretation of Weber are also used; Michael Zurn (2004), for example, refers to legitimacy as “... a fundamental normative validity to justify the exercise of authority, the latter refers to the social acceptance of expressions of authority", while Sylvia Karlsson ( 2016) states that "the ability [of the authorities] to outline normative arguments that provide a coherent justification for that authority is fundamental for a society that wants to reflect its fundamental values". The characteristic elements that emerge are certainly evident and are summarized in how much social acceptance a government system has by the people who live under its tutelage.

Having reached this point, it is necessary to mention that the notion of legitimacy does not establish a direct relationship with "legality" because what is legitimate is not always legal, nor vice versa. Something is legal insofar as it adheres to a legal norm issued by an authority, but if that legal norm is not socially accepted as "valid", then it cannot be considered legitimate. And in the opposite sense, certain social actions can go against the legal norms of a society, and even then, consider themselves legitimate as long as people consider that these social actions, due to different factors, are "fairer" than the laws themselves (a rebellion, for example).

Now, Max Weber is going to distinguish three types of specifics of what he comes to consider legitimate domination. The first is a type called "traditional domination", whose foundations of legitimacy rest on the conception that the prevailing system is the consequence of an order that, as its name implies, traditionally always existed. In this type of domination there is almost no questioning of the institutions because they become sacred to such a point that "their administrative apparatus is not made up of officials but of personal servants; the relationship between the administrative staff and the lord is one of personal fidelity, not of an impersonal position" (Martínez-Ferro, 2010). It can be said that, in this type of domination, society conceives institutions as the highest degree in the hierarchy of legitimacy, since they have always existed. Below them would be the president on duty because he was placed there by the criteria themselves from the traditional institution that represents 
the vision of order that that society conjures up, and finally the laws that obey the will of the president.

The second is the type of domination called charismatic, whose principle of domination is that the current ruler is considered a person with such special characteristics that they distinguish him from other people, enough to be considered the most suitable person to rule. As the acceptance of authority is concentrated in this person, then the administrative apparatus of the most important institutions is made up of his followers and his trusted men; and this is especially interesting because, in contemporary societies, using the power of a public office to place acquaintances in important positions is a punishable action and rejected by society; however, in this type of system it is completely valid. When the notion of legitimacy is rooted in the charisma of the current ruler, it can be deduced that this is the most volatile and least durable system, since once this ruler is replaced by another, nothing ensures that the new ruler possesses the same charisma and acceptance by society. And things get more complicated when these characteristics that made the first ruler extraordinary come from personal feats (for example, military conquests) that perhaps overshadow the next ruler, thus weakening the entire structure of legitimacy of the system.

The third is called "legal domination", and it is the most rational way of exercising domination, properly of modern states. In this type of domination, it is society itself that comes together; and by means of a whole bureaucratic apparatus, it establishes the foundations or the orders under which they want to live. The rulers of the day must adhere to these regulations that will often serve as a limit to the power of the president. In this case, it is no longer possible to access positions in the administrative apparatus thanks to a favor from the ruler, but rather it is necessary to carry out an entire professional career that allows one to climb positions. And the work for the state is carried out by virtue of a contract that defines the field of action, preventing the exercise of authority in areas outside those that have been hired.

The latter is the prevailing type of domination in the $21 \mathrm{st}$ century and conceptually it would be expected that, as it is the most complexly constructed type of domination and basing its values on the maximum degree of rationality achieved by men, this is the order with the greatest legitimacy enjoy; but as mentioned above, there are great social upheavals that account for a serious legitimacy problem that will not necessarily overthrow the entire system, but rather requires substantial modifications that are capable of solving the most outstanding problems, than in Latin America, society attributes corruption and the inefficiency of its authorities as one of its main causes.
The configuration of the problem is then more diffuse than it appears. An understanding of Inca society could give us a more clarifying vision of a pragmatically legitimate system.

\section{FUNDAMENTAL CHARACTERISTICS OF THE INCA STATE}

The state of the Incas was clothed with a sacred character, since their highest authority, the Sapa Inca, was considered a descendant of the divinity that ruled the world in the Inca conception. The Inca was practically a god, so his will was respected by the entire nation, or at least it was intended.

This multinational imperial state increased its dominance through military conquests and diplomatic treaties that did not always end in bloodshed. The idealistic justification that the Incas attributed to their expansionist need was rooted in the conception that they had of themselves when building "a propaganda apparatus and a 'history' in which they appeared as the organizing people of the Andean world, thanks to whose wisdom they removed it chaos" (Espinoza Soriano, 1997), but the practical reality that forced them to conquer and annex new territories was another.

The Incas practiced a system of succession of power called "correinado". The heir to the throne was chosen from among the Inca's children, although not necessarily from the coya or main wife, but "it was enough to have one of the Inca elite as a mother to become an Inca" (Regalado de Hurtado, 1996) and the chosen one, upon reaching the necessary age "had the opportunity to prove himself as a co-emperor" (Kulmar, 2010) and depending on the demonstrated abilities he was confirmed as the next emperor or alienated from the possibility of acquiring such a title, for what "the correinado system did not imply a binding obligation with the person chosen for the succession in command" (Rostorowski, 2001). Once the new Inca assumed the throne, the previous one did not inherit land or wealth since these were made available to his panaca, which was the royal family of the Inca. That is to say, the new Inca had the need to conquer new lands and wealth in order to build his own heritage, that was one of the main causes of the enormous need to expand the Inca territory on behalf of the Inca ruler of the day, which also contributes to the legitimacy of the sectors of power since "the prestige of culture and power are closely linked. Every victorious war favors cultural prestige" (Aron, 1981)

In the aspect referred to the succession, the Incas configured a system that mixed elements of the traditional and charismatic form of domination mentioned by Weber. The Inca system of succession greatly corrects the main 
weaknesses of the two types of domination mentioned. The Inca rulers are sacred because they are children of divinity, that is, elements of traditional domination are presented while the state institution is venerated with a sacred character and it is understood that their order is closely related to the understanding of the cosmos and the order of the world. However, it is inevitable that the charisma and efficiency of the Inca play an important role in the approval that he would receive from his subjects, and on a larger scale, of the legitimacy of the system.

The Inca is understood as a sacred and charismatic ruler, but that is not why he is exempt from all criticism. Huiracocha's case is a perfect example; Since this Inca, when fleeing from Cuzco, the capital of the Inca empire, due to the threat of the rival Chanca society, fell into enormous disrepute, and although he himself had appointed Inca Urco as the new ruler, his own children and captains were opposed such a decision (Hernández Astete, 2012). From this particular scenario, it can be concluded that faith in the Inca was not blind, but was open to questioning, which means that its efficiency was put to the test. In addition, one of the main risks of traditional domination is that an incompetent person rises to power because the institution "so orders it", and this incompetence is going to capitalize on measures so inefficient that they end up questioning the population towards the legitimacy of the system and subsequent uprising. At the other extreme of this type of domination, there is a risk that someone who does have sufficient capacities for the position, but who does not have the "blessing of the institutions", will rise to power; in short, a capable but illegitimate ruler. Can then find an intermediate point in which the ruler is skilled and also has characteristics that do not threaten the profile of legitimate ruler that the institutions required? It seems that the correinado system of the Incas succeeded, or at least came very close.

This system was configured in such a way that the Inca was a person blessed by the institutions inasmuch as he was a descendant of another Inca, son of the divinity, and he was also a person capable enough to exercise the position after having approved the stage of the correinado. In this regard, the fact that the notion of legitimate or illegitimate child does not exist helped a lot, since it greatly expanded the range of possibilities among all the Inca's offspring.

This ability that is so much alluded to by the Inca to maintain a good government had to be capitalized on an unrestricted respect for the laws and a dignified lifestyle for the people.
In the case of the laws, being a society without writing, they do not have a specific or highly elaborated legal body. Jorge Basadre (1936), one of the first researchers on this issue, mentions that in this type of society the laws are disseminated through phrases or words that are easy to remember and internalize in people's memory, in the case of the Incas these phrases they would have been the emblematic "ama sua", "ama llulla", "ama qella" (Don't be a thief, don't be a liar and don't be lazy, respectively). Although ultimately there should have been more sayings that have served as legal propaganda.

The laws were obviously not the same for everyone, they were more drastic for those who were lower in the pyramid of social stratification; In addition, the Incas had the policy of respecting the customs of the peoples they conquered, so that the notions of justice of these peoples could intermingle with those of the Incas and result in a not so uniform law throughout the Inca empire. Hence, we speak of Inca rights instead of Inca law.

With regard to crimes, its conception was much more complex than it appeared, since a crime did not simply mean the violation of a legal body, but mainly an attack against the very sacred order of the world and a challenge to the divinities that govern the universe. If the laws find their origin in a divinity, then the laws are themselves divine, and in a society where religion has as much power as Inca society, this did nothing but strengthen the coercive action of the laws considerably. All this would end up leading to lower rates of violation of the laws, Franklin Pease (1971) mentions in this regard that "It is not surprising then that the rebellion against the state was severely punished, since it meant the violation of the fundamental and sacred order." This constitutes another important indicator that a society views the system in which it operates as legitimate.

But all this ideological conception about the divinities and the sacred order of things would not find, or at least would hinder its pragmatic acceptance if hunger and misery were present in society. The Incas knew how to sustain a redistribution system capable of storing resources to support the sectors of society that were not directly engaged in production (such as the aristocracy, specialized artisans, the disabled, among others).

For this purpose, they had the good sense not to despise the technological achievements of the societies they conquered, but to acquire and perfect them as far as possible. An example is the construction of platforms in places with steep slopes that were able to expand their agricultural production so much (Lumbreras, 1969). But it is necessary to place special emphasis on the vision and administration that they handled over the available 
workforce. Work was the main form of subsistence in Inca society under its elemental forms of: ayni (reciprocal work between relatives), minka (work for the benefit of the community as a whole) and mita (work for the state in the form of tax). Of particular interest are the first and last forms mentioned.

In the case of the ayni, not having enough resources to carry out daily tasks, such as harvesting or repairing a house, was not a serious problem because only one member of the family network groups had to be used (ayllu) to borrow their labor and thus get out of the complications that it presents. Of course, the benefactor would ask for the same benefit when he needed it.

If a person received help and, in the future, refused to return it, then no member of the ayllu would ever come to their aid again, for this reason Waldemar Espinoza (2010) states that not returning the work received was practically condemning themselves to begging, because before in any eventuality, help could not be received from family members who, in a society without currency to hire labor, was so important. In other words, at the family or ayllu level, work was so internalized in everyday life to the point of being understood as a fundamental activity of social life.

In the case of the mita, this work was carried out on state lands and mines, and even here the system was configured in such a way that taxpayers do not pay their taxes with reluctance or resentment towards the state; On the contrary, work for it with enthusiasm and satisfaction. This is because, during mita seasons, workers received food and chicha (a very important drink in this society) from the state so they did not have to spend their own food reserves that ended up being a "savings" ; In addition, the tasks were accompanied by humorous celebrations that were at the expense of the state and that did nothing more than fan the spirits of the workers, and of course, the most efficient were rewarded even with textiles (an important distinctive in this society) and women.

It is also necessary to mention that the social stratification itself allowed the accumulation of production surpluses for certain important figures, but these were not viewed with envy or suspicion, but with prestige since their wealth was destined to be redistributed in times of crisis. For this reason, the one who had the most was well considered, because he would be the one who would help the population the most in difficult times.

Obviously, the lands for these privileged classes and the common population were managed intelligently enough to leave no one without the possibility of working for a living. Hence Kevin Harris (2007) mentions that "once a community had enough land to support itself, the rest was turned over to the state."

And to this configuration of work must be added the fact that the Incas, when conquering new peoples, not only learned from what they excelled at, but also taught them to correct what they faltered in. For this reason, "every conquest was accompanied by a teaching process aimed at learning the proper construction of houses, the cultivation of the land, and the use of water from the planning of ditches and irrigation systems" (Vargas Callejas, 2001).

It is then plausible to think that the entire empire benefited from the productive tools collected by the Incas, and this added to the ideology of work that they spread, represented an increase in production at a rate sufficient to offer a decent life to the common population, attacking thus any ghost of illegitimacy of the system that could be related to inefficiencies in the administration of resources by the Inca state.

Finally, I would like to mention a last notion of legitimacy, that of Nicolás Fleet (2007), who argues that:

Legitimacy allows us to understand how it is possible that, despite conflict and domination, that is, the imposition of particular interests, the social order remains valid for its members, who by submitting to it give legitimacy to the inequalities and asymmetries that such order constitutes and to the mandates that flow from it.

It is clear that inequalities existed in Inca society and the accumulation of wealth was allowed for a few while it was a conception even impossible to imagine for others; even so, the administrative measures that were handled in the system and the economic results achieved; In addition to the complex ideological apparatus that served as a support, they allowed to build a society where these inequalities were not seen as something unfair, but rather the consequences of a divine order and an authoritarian system that could justify its position in power, both ideologically and pragmatically. What a different vision from the one that some chroniclers who, when they began to write about the Incas, tried to make them look like tyrants who were erected under an illegitimate system to try to justify the imposition of Spanish order on the Inca (Morong Reyes \& Brangier Peñailillo, 2019).

\section{DISCUSSION}

It is necessary to deal with a fairly important and controversial subject. When the Spanish conquerors arrived in the Andean lands, there were certain tribes dominated by the Incas who joined the Spaniards to defeat the Incas. Is it conceivable that in a system of domination 
considered "legitimate", the dominated themselves are one of the sectors that promote the fall of the government system? The answer is definitely negative.

History has shown that great social uprisings occur precisely because there is an important sector (it can also be called social class) that does not consider the government system legitimate for various reasons. In that case, what did the Cañaris, Chachapoyas, Huancas and other tribes that supported the Spanish consider illegitimate? At this point it is necessary to make a parenthesis. Current studies show that the main factor that led to the fall of the Incas was neither the betrayals received, nor the arms superiority of the Spaniards, but the diseases brought by them.

But this does not mean that the betrayal of various tribes is not a symptom of illegitimacy of the system, because it is, even if it were not so decisive in the fall of the government. In the case of illegitimacy, intentions and perception matter more than the final result, and in this case, the intention of those tribes was ultimately to overthrow the Incas. This is where the first moment of illegitimacy in the Inca empire is recognized, and presumably this was due to a lack of social and ideological cohesion.

The Incas did not precisely make an attempt to unify the peoples they dominated, their main mode of ideological submission was to impose their own god, the sun god, as the main divinity and otherwise they allowed them to continue with their other traditions. To what extent does diversity influence the legitimacy or illegitimacy of the system? Is the conqueror's system that imposes his worldview on the dominated more legitimate? Or is it the one who respects the diversity of the people he dominates? It follows from the Inca experience that none of the above questions can by itself constitute a definitive answer.

Cultural diversity is very important, especially because if there is an attempt to violently and arbitrarily impose a very different culture on another, it cannot be expected that there will be a peaceful symbiosis, but on the contrary, there will be constant conflicts that will not do more that illegitimate all types of government. The different revolutionary movements of the XVII century in Peru led by mixed races and indigenous people against the Spanish attest to that. But we also see that the lack of social cohesion fostered by the Incas was precisely what led other tribes to betray them. And here it is necessary to emphasize a fairly important detail, not all kinds of cultural "diversity" should be understood equally. There is the possibility of having different cultures under the same system of domination and this does not automatically make it illegitimate, what does make it so is the contradiction of ideas and values between these different cultures compared to the system of domination under which they live. It is precisely the contradictions that make diversity become illegitimate, and not diversity itself.

In the case of the Incas; The Cañaris, Chachapoyas, Huancas and other tribes, both because of the violent conquest they suffered, and because of the enormous difference in the way of life they practiced in front of the Incas, there was a permanent contradiction that the Inca government system could not recognize, that was precisely one of the main legitimacy problems that can be recognized in this vast empire.

\section{CONCLUSION}

The scope of this paper is conservative compared to the multiple perspectives from which the issue of the legitimacy of the Inca system can be approached. The further disaggregation of the issue, the understanding is probably also more enriching, as long as an isolated element is not taken as a generalizer of the system, but is studied according to its interrelation with other elements. Many elements are missing to analyze, such as the establishment of "mitimaes", the policy of maintaining the prestige of conquered elite rulers or perhaps the distribution of "tupus" of different size but equivalent productivity and its consequences on the legitimacy of the Inca system under the optics of the dominated, among others. But the general idea that is intended to be outlined is not necessarily summarized in a basic sentence such as "it was a legitimate system" or "it was not a legitimate system", rather it is a call to understand the elements that could validate the Inca system in its development context and in what moment of human evolution these elements were distorted and ended up leading to the muchconvulsed Latin American society of the XXI century. Many attempts to explain the contemporary situation argue that human societies evolved in such or such a way and therefore we must understand it from such or such a perspective, but the reality is that we still do not fully understand such evolution and that is where the sciences dedicated to understanding and reconstruction of the social evolutionary process can contribute so much, not only to serve as empirical evidence for some explanations that try to understand social behavior, but also to classify other highly dissociated explanations of reality as obsolete. Whatever the case, the understanding of the past will always be fundamental for the understanding of the present and the company of projection towards the future. 


\section{REFERENCES}

[1] Aron, Raymond. (1981). Max Weber y la política de poder. Papers: Revista de Sociología, 33-53. http://dx.doi.org/10.5565/rev/papers/v15n0.1229

[2] Basadre, Jorge. (1936). La Ley del Inca. Revista de la Universidad Católica del Perú, 235-248. http://repositorio.pucp.edu.pe/index/bitstream/handle/12345 6789/52973/la\%20ley\%20del\%20inca.pdf?sequence=1\&isA llowed=y

[3] Espinoza Soriano, Waldemar. (1978). Los modos de producción en el imperio de los incas. Mantaro.

[4] Espinoza Soriano, Waldemar. (1997). Los incas. Mantaro.

[5] Espinoza Soriano, Waldemar. (2010). Economía política y doméstica del Tahuantinsuyo. In C. Contreras (Ed.), Economía Prehispánica (pp. 315-442). Lima: Instituto de Estudios Peruanos. https://www.bcrp.gob.pe/docs/Publicaciones/libros/historia/ economia/1-economia-prehispanica.pdf

[6] Fleet, Nicolás. (2007). Racionalización y poder. La cuestión de la legitimidad en Weber como referente de la acción política. Revista Temas Sociológicos, 215-250.

[7] Harris, Kevin R. (2007). Was the Inca Empire A Socialist State? A Historical Discussion. Historia, (16), 54-60. https://www.eiu.edu/historia/Harris.pdf

[8] Hernández Astete, Francisco. (2012). Succession Among the Incas. Chungara, 655-667. http://dx.doi.org/10.4067/S0717-73562012000400008

[9] Karlsson-Vinkhuyzen, Sylvia. (2016). Legitimacy. In C. Ansell, \& J. Torfing, Handbook of Theories of Governance (pp. 194-204). Massachusetts: Edward Elgar. https://www.academia.edu/35552858/Legitimacy

[10] Kulmar, Tarmo. (2010). About the Comparison of the State Authority and Social Organization by Incas and Aztecs. Folklore: Electronic Journal of Folklore, (45), 137-150. http://doi.org/10.7592/FEJF2010.45.kulmar

[11] Lumbreras, Luis Guillermo. (1969). De los pueblos, las culturas y las artes del Antiguo Perú. Francisco Moncloa Editores. Perú.

[12] Martínez-Ferro, Hernán. (2010). Legitimacy, domination and law in the sociological theory of Max Weber state. Estudios $\quad$ socio-jurídicos, 12(1), 405-427. https://revistas.urosario.edu.co/index.php/sociojuridicos/arti cle/view/1198/1135

[13] Morong Reyes, Germán \& Brangier Peñailillo, Víctor. (2019). The Incas as model of subjection. Gobierno del Perú and the ethnographic writing of the colonial judge of Charcas, Juan de Matienzo (1567). Estudios atacameños, (61), 5-26. http://dx.doi.org/10.4067/S0718 10432019005000102

[14] Oro Tapia, Luis. (2002). La idea de legitimidad en Max Weber, Carl Schmitt y Guglielmo Ferrero. Boletín Jurídico de la Universidad Europea de Madrid. http://hdl.handle.net/11268/5039

[15] Beltrán, Francisco. (2001). Legitimidad, dominación y racionalidad en Max Weber. Economía y sociedad, 5(8), 187-200.
[16] Pease, Franklin. (1971). Aproximación al delito entre los Incas. Derecho PUCP, (29), 52-62. https://doi.org/10.18800/derechopucp.197101.004

[17] Regalado de Hurtado, Liliana. (1996). Sucesión incaica. Lima: PUCP - Fondo Editorial.

[18] Rostorowski, María. (1991). Pachacútec. Lima: Instituto de Estudios Peruanos.

[19] Vargas Callejas, Germán. (2001). Memoria de los Andes. Notas sobre la educación en la cultura inca. Sarmiento, 4564.

[20] Zürn, Michael. (2004). Global governance and legitimacy problems. Government and Opposition, 39(2), 260-287. https://doi.org/10.1111/j.1477-7053.2004.00123.x 